\title{
Influence of organic matter from urban effluents on trace metal speciation and bioavailability in river under strong urban pressure
}

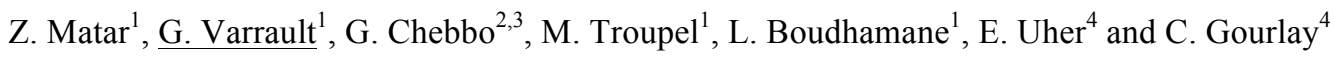 \\ ${ }^{1}$ Université Paris-Est, LEESU MA 102 - 61 av. du Gal de Gaulle, 94010 Créteil Cedex, France, varrault@u-pec.fr, \\ matar@leesu.enpc.fr \\ ${ }^{2}$ Université Paris-Est, LEESU UMR MA 102 - F-77455 Marne La Vallée 2, France, chebbo@leesu.enpc.fr \\ ${ }^{3}$ Lebanese Univesity, Faculty Enginering, Lebanon, NH USA, gksc@terra.net.lb \\ ${ }^{4}$ IRSTEA, Unité Rech Hydrosyst \& Bioprocédés, F-92613 Antony, France, catherine.gourlay@irstea.fr
}

\begin{abstract}
In aquatic systems, dissolved organic matter (DOM) constitutes a key component of the carbon cycle controlling the transport, speciation, bioavailability and toxicity of trace metals. In this work, we study the spatio-temporal variability of the MO in terms of both quality and quantity from upstream to downstream the Parisian conurbation. Urban discharges which are the main source of allochthonous organic matter into the Seine at low water periods were also investigated. The DOM collected was fractionated according to polarity criteria into five fractions: hydrophobic, transphilic, hydrophilic acid, hydrophilic basic and hydrophilic neutral. Due to urban discharges a strong enrichment in the hydrophilic (HPI) fraction was observed for downstream sites. This hydrophilic fraction presented stronger binding capacities for copper than hydrophobic fraction from less urbanized site (upstream from Paris) and than Suwannee river fulvic acid (SRFA). Furthermore, biotests highlighted a significant copper bioavailability decrease in presence of hydrophilic DOM.
\end{abstract}

Key words: Hydrophilic organic matter, urban discharges, trace metals, speciation, bioavailability.

\section{Introduction}

In aquatic systems, trace metals are present in different chemical forms. These forms determine not only the residence time in the different compartments of the environment, but also the bioavailability or toxicity of the metal towards living organisms (Town and Filella, 1999). Dissolved Organic Matter (DOM) plays a key role in the circulation of trace elements in the environment. Complexation to DOM can either hinder metal precipitation or facilitate remobilisation of metals from the sediments, thus allowing their dissemination (Buffle et al., 1990). Moreover, metal complexation to DOM modifies the speciation of metals and their toxicity (Tessier and Turner, 1995).

Over the past few decades, many studies have analysed the capacity of DOM to complex metal ions in natural waters. Most published data have focused on the humic and fulvic part of DOM (the hydrophobic acid fraction) and have highlighted the relevance of these substances in the metal complexation. Humic substances (hydrophobic acids), are natural complex organic macromolecules composed of aromatic cycles connected by aliphatic chains and functional groups of acidic nature. This hydrophobic fraction of DOM, is isolated at acidic pH on DAX-8 resin (Thurman and Malcolm, 1981). It is often considered as the major part of DOC (Dissolved Organic Carbon) in most natural aquatic systems, while the hydrophilic fraction of organic matter, not absorbed on DAX-8 and XAD-4 resins, is generally a minor part (Croue, 2004). For this reason, it has been considered that binding capabilities of the hydrophilic fraction could be neglected whenever metal speciation is computed in most natural aquatic systems.

However, the hydrophilic fraction in waters flowing through densely populated areas can increase to almost $50 \%$ of DOC (Imai et al., 2002; Pernet-coudrier et al., 2008; Pernet-Coudrier et al., 2011) as a result of various urban DOM discharges (treated or untreated wastewater) and the strong primary productivity induced by these discharges. Given the difficulty to extract and purify the hydrophilic fraction, these non-humified organic 
materials are poorly studied (Labanowski, 2004; Violleau, 1999) and their influence on metallic speciation, bioavailability and toxicity are very poorly characterized particularly in aquatic systems under strong urban pressure. In a recent investigation (Pernet-coudrier et al., 2008), we highlighted the high trace metal binding ability of the hydrophilic fraction of treated effluent organic matter compared to fulvic substances (Suwanee River Fulvic Acid from IHSS). This work demonstrate that, when computing trace metal speciation within "urbanized" aquatic system, it is essential to also consider the binding abilities of the hydrophilic organic matter despite its low aromaticity. Our primary objective is to study DOM from urban discharges (combined sewer overflows and treated effluents from waste water treatment plants) and from receiving waters (upstream and downstream Paris). DOM in samples is fractionated according to polarity criteria (Croue, 2004). Obtained fractions are characterized by means of various analyses (DOC, spectroscopic UV and spectrofluorescence). Our second goal is to study the influence of every DOM fraction on copper bioavailability. Since the speciation of dissolved metals strongly affects their biological availability, i.e. their capacity to reach the biological target (Tessier and Turner, 1995), a biotest based on an acute toxicity test using Daphnia Magna has been applied to assess the influence of each DOM fraction on metal toxicity and bioavailability.

\section{Materials and Methods}

A monthly sampling campaign (30 samples) has been undertaken over a period of twelve months (October 2010- September 2011) in order to assess the spatiotemporal variability of DOM in receiving waters and the potential impact of urban discharges. Sampling sites were located upstream Paris ("Ussy-sur-Marne" on the river Marne and "Fontaine-le-port" on the river Seine) and downstream Paris ("Andresy").

Ten campaigns (20 samples) have been carried out in order to sample treated effluents of five different waste water treatment plants (WWTP- with different waste water treatment methods) in Parisian conurbation.

Furthermore, during rainstorm events, in combined sewer, the WWTP capacity may be exceeded and the water overload is discharged to the river without any treatment. A major wet weather outlet in this system is located on the right bank of the river, at the Clichy pretreatment plant (more than $75 \%$ of the sewage water from Paris and its suburb). The combined sewer overflow (CSO) discharge was sampled with an automatic sampler equipped with a cooled $\left(4^{\circ} \mathrm{C}\right)$ compartment. An average sample is reconstituted by the assembling of subsamples collected every $6 \mathrm{~min}$ over $30 \mathrm{~min}$ into glass 1-L bottles. CSO were processed within $3 \mathrm{~h}$ after collection of the last sample. Nine discharges were sampled between June 2010 and September 2011.

For all these samples, DOM was fractionated according to polarity criteria. Samples of about 10 liters were first filtered $(0.45 \mu \mathrm{m})$ and then acidified and filtered on nonionic macroporous DAX-8 resins and XAD-4. This allows us to fractionate DOM into different fractions according to polarity criteria: hydrophobic (HPO) and transphilic (TPI) fractions are retained respectively onto DAX-8 and XAD-4 resins (Croue, 2004). Basic and acid hydrophilic (HPI) fractions are respectively retained onto cationic exchange resin (AGMP-50) and anionic exchange resin (AGMP-1). The neutral hydrophilic fraction, not retained by any resins, is in the effluent. This protocol allows us to fractionate DOM into five fractions according to polarity criteria: hydrophobic (HPO), transphilic (TPI) hydrophilic basic (HPI-B), hydrophilic acid (HPI-A) and hydrophilic neutral (HPI-N) fractions. Various physico-chemical analyses were carried out to characterize the isolated fractions (DOC, spectrofluorescence, SUVA...).

Copper binding abilities of each isolated organic fraction were assessed using potentiometric methods (ISE). Each fraction was titrated by increasing additions of copper at $\mathrm{pH}=8$ in $0.1 \mathrm{M} \mathrm{KNO}_{3}$. The concentration of free copper is determined using a copper specific electrode. Given the strong influence of $\mathrm{pH}$ on the copper complexation by DOM, a constant $\mathrm{pH}(0.1 \mathrm{pH}$ unit $)$ must be maintained throughout the duration. Data obtained from each DOM fraction titration were modeled using Langmuir isotherm with a discrete distribution of two or three mono-dentate binding ligands ( $\mathrm{Li}$ ), each defined by 2 parameters: a total site concentration and a conditional stability constant.

Influence of each isolated organic fractions on copper bioavailability was assessed with acute toxicity tests on Daphnia Magna (ISO 6341). Daphnids are exposed for 24 hours at different concentrations of copper in the presence of the different organic matter isolated fractions (Tusseau-Vuillemin et al., 2004). The media tested were inorganic medium (water Volvic) and organic media (2 mg C.L ${ }^{-1}$ ). For each medium, copper solutions at different concentrations and control were prepared. Daphnids are then added in these solutions and are placed in a thermostatic chamber at $21^{\circ} \mathrm{C}$. The number of immobilized daphnids is determined 24 hours after starting bioassay. The dose-response curves and the toxic concentration for $50 \%$ of the EC50 are obtained by a linear fit of experimental data using the logistic model REGTOX.

All of these tests were carried out in order to compare properties of DOM from non urbanized areas (upstream Paris and SRFA as a fulvic reference) with DOM collected from urban discharges.

\section{Results and Discussion}

At low water periods, surface waters studied show DOC concentrations varying from $2.2 \mathrm{mg} \mathrm{C} \mathrm{L}^{-1}$ to $3.4 \mathrm{mg} \mathrm{C} \mathrm{L}^{-1}$ from upstream to downstream of the Paris area (Fig. 1). Increase of DOC downstream Paris is principally due to urban discharges (about 10-15 $\mathrm{mg} \mathrm{C} \mathrm{L} \mathrm{L}^{-1}$ for the treated effluent of the main Parisian WWTP). Furthermore, the 
surface waters DOM displays a more pronounced hydrophobic character upstream (41\% HPO and 33\% HPI for Ussy-sur-Marne and 39\% HPO and 34\% HPI for Fontaine-le-port) than downstream Paris (35\% HPO and $45 \%$ HPI for Andresy). This increase of the hydrophilicity downstream Paris is attributed to urban discharges. Indeed, the DOM collected from urban discharges (CS0s and WWTP effluents) display strong hydrophilic characteristics, low humic substance contents (Fig. 1), low SUVA and high contents of protein compounds. These results highlight the influence of urban discharges on the receiving waters DOM quality.

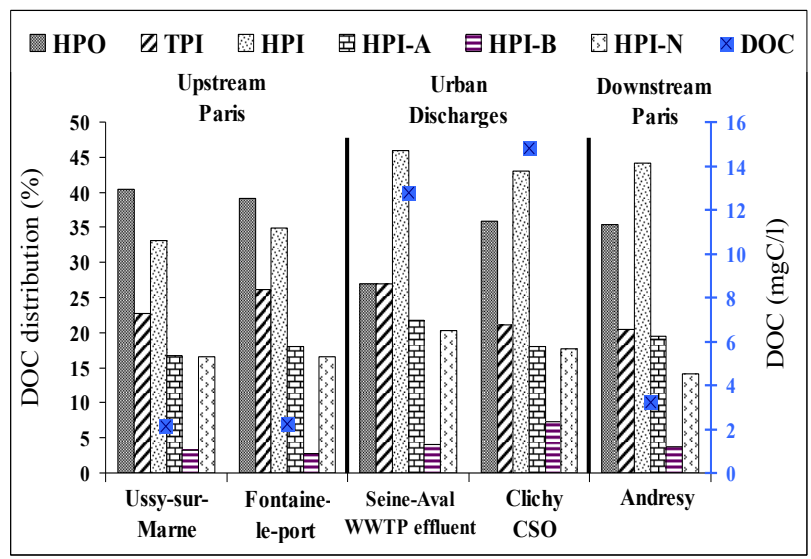

Fig. 1. DOC (mg C L $\left.{ }^{-1}\right)$ and distribution of DOC (\%) at low water periods in receiving waters of the Parisian conurbation and urban discharges.

As it can be seen on the figure 2, DOM from urban discharges and from downstream sites present high binding capacities for copper compared to DOM from the least urbanized sites (upstream Paris and SRFA). These results also indicate a difference in the copper binding ability according to the different organic fractions; hydrophilic fractions have a higher binding ability than hydrophobic and transphilic fractions (Fig. 2).

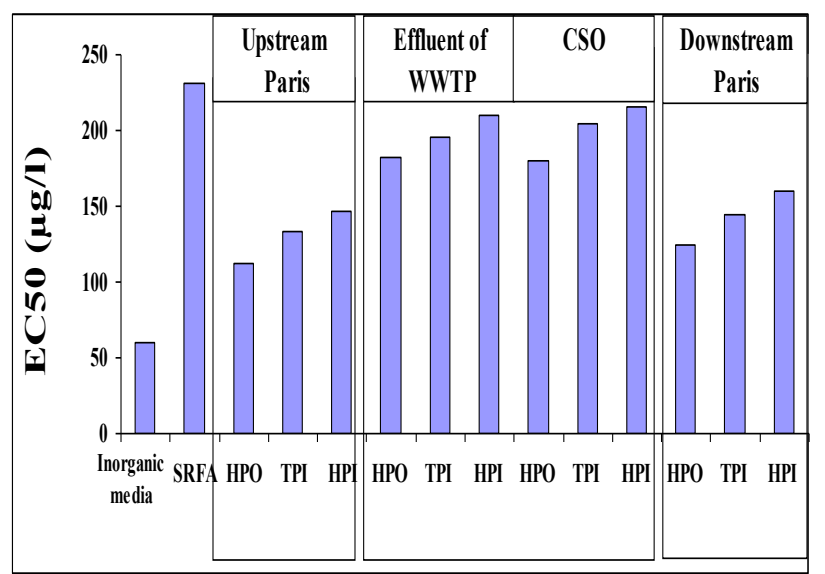

Fig. 2. Copper titrations of different DOM (nonfractionated) and different $\mathrm{DOM}$ fractions at $\mathrm{pH}=8$ in 0.1 $\mathrm{M} \mathrm{KNO}_{3}$.

Furthermore, the protective effect of organic matter towards the toxicity of copper to Daphnia magna is clearly highlighted where we show a significant copper bioavailability decrease especially in presence of hydrophilic DOM from urban discharges. Indeed, EC50 expressed as total copper in an organic matrix is much higher $\left(150 \mu \mathrm{g} \mathrm{L}^{-1}\right)$ than inorganic matrix $\left(60 \mu \mathrm{g} \mathrm{L}^{-1}\right)$. As it can be seen on the

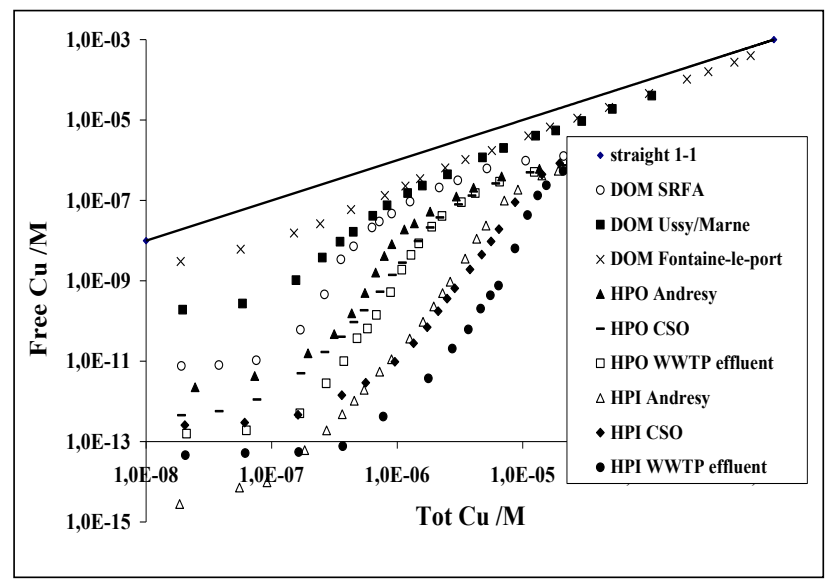

Fig. 3. Copper EC50 ( $\left.\mu \mathrm{g} \mathrm{L}^{-1}\right)$ obtained for each isolated organic fraction and for inorganic media

-EC50 obtained for DOM from urban discharges and SRFA are not statistically different indicating a real protective effect of urban DOM similar to the naturally hydrophobic DOM -EC50 obtained for DOM from urban discharges appears to be larger than those obtained for DOM from non-urbanized sites (upstream of the Paris area).

\section{Conclusion}

This study highlights that in rivers under strong urban pressure, the hydrophilic DOM may be the main component of DOM especially at low water periods. On the opposite, humic substances are a minor part of DOM. This is due, for one part, to urban discharges. This study confirms our first results showing a strong influence of hydrophilic DOM from WWTP effluent on the trace metal biogeochemistry. Furthermore, for the first time, this study demonstrate that DOM from CS0s contain also high proportion of hydrophilic organic matter with high binding capabilities and then with strong influence onto trace metal speciation and bioavailability within aquatic systems. This is why, it is essential to also consider the binding capabilities of hydrophilic organic matter when computing trace metal speciation and bioavailability within aquatic system under strong urban pressure.

\section{Acknowledgements}

The Scientific programs OPUR (http://leesu.univ-parisest.fr/opur/) and PIREN-Seine (http://www.piren-seine.fr) are acknowledged for their financial support. SIAAP (Syndicat Interdépartemental pour l'Assainissement de l'Agglomération Parisienne) is also acknowledged for its technical support. 


\section{References}

Buffle, J., R. S. Altmann, M. Filella, and A. Tessier (1990), Comlexation by natural heterogeneous compounds - site occupation distribution-functions, A normalized description of metal complexation, Geochimica Et Cosmochimica Acta, 54(6), 15351553.

Croue, J.-P. (2004), Isolation of humic and non-humic NOM fractions: structural characterization, Environmental monitoring and assessment, 92(1-3), 193-207.

Imai, A., T. Fukushima, K. Matsushige, Y. H. Kim, and K. Choi (2002), Characterization of dissolved organic matter in effluents from wastewater treatment plants, Water Research, 36(4), 859-870.

Labanowski, J. (2004), Matière organique naturelle et anthropique : vers une meilleure compréhension de sa réactivité et de sa caractérisation, Université de Limoges.

Pernet-coudrier, B., L. Clouzot, G. Varrault, M.-H. Tusseau-vuillemin, A. Verger, and J.-M. Mouchel (2008), Dissolved organic matter from treated effluent of a major wastewater treatment plant: Characterization and influence on copper toxicity, Chemosphere, 73(4), 593-599.

Pernet-Coudrier, B., E. Companys, J. Galceran, M. Morey, J.-M. Mouchel, J. Puy, N. Ruiz, and G.
Varrault (2011), Pb-binding to various dissolved organic matter in urban aquatic systems: Key role of the most hydrophilic fraction, Geochimica Et Cosmochimica Acta, 75(14), 4005-4019.

Tessier, A., and D. R. Turner (1995), Metal speciation and bioavailability in aquatic systems, edited by B. J. a. V. L. H. P., Chichester, John Wiley \& sons.

Thurman, E. M., and R. L. Malcolm (1981), preparative isolation of aquatic humic substances, Environmental Science \& Technology, 15(4), 463466.

Town, R. M., and M. Filella (1999), Metal ion complexation by micro-organisms in natural waters: A critical assessment of thermodynamic (and kinetic?) aspects, Abstracts of Papers of the American Chemical Society, 217, U854-U854.

Tusseau-Vuillemin, M. H., R. Gilbin, E. Bakkaus, and J. Garric (2004), Performance of diffusion gradient in thin films to evaluate the toxic fraction of copper to Daphnia magna, Environmental Toxicology and Chemistry, 23(9), 2154-2161.

Violleau (1999), Intérêt du fractionnement et de l'extraction des matières organiques naturelles d'eaux de surface pour l'étude de leur propriétés structurales et de leur pouvoir complexant vis-à-vis du cuivre" Laboratoire de chimie de l'eau et de l'environnement, Université de Poitiers. 